\title{
Integrating Sustainability in the Fashion System Using Association Rules
}

\author{
Filippo Emanuele Ciarapica, Ilaria De Sanctis, Barbara Resta, \\ Stefano Dotti, Paolo Gaiardelli, Romeo Bandinelli, Virginia Fani \\ and Rinaldo Rinaldi
}

\begin{abstract}
This work aims at analysing the environmental strategies developed by fashion companies in order to identify the most important stakeholders involved in the strategy, the environmental practices carried out and the competitiveness impacts. A conceptual model, based on Association Rules (AR), has been proposed for investigating the network of influences among the environmental strategy, the environmental management practices and the environmental competitiveness and profitability of the companies. The research has been conducted through a survey submitted to fashion companies operating in Textile, Clothing and Leather (TCL) sectors. Results indicate that "customers" and "suppliers" are the most
\end{abstract}

\footnotetext{
F.E. Ciarapica · I. De Sanctis

Dipartimento di Ingegneria Industriale e Scienze Matematiche,

Università Politecnica delle Marche, Via Brecce Bianche, 60100 Ancona, Italy

e-mail: f.ciarapica@univpm.it

I. De Sanctis

e-mail: i.desanctis@univpm.it

B. Resta · S. Dotti · P. Gaiardelli

CELS-Research Group on Industrial Engineering, Logistics and Service Operations,

Department of Management, Information and Production Engineering,

University of Bergamo, Viale Marconi 5, 24044 Dalmine (BG), Italy

e-mail: barbara.resta@unibg.it

S. Dotti

e-mail: stefano.dotti@unibg.it

P. Gaiardelli

e-mail: paolo.gaiardelli@unibg.it

R. Bandinelli (四) · V. Fani · R. Rinaldi

Department of Industrial Engineering, University of Florence,

Viale Morgagni 40, 50134 Florence, Italy

e-mail: romeo.bandinelli@unifi.it

V. Fani

e-mail: virginia.fani@unifi.it

R. Rinaldi

e-mail: rinaldo.rinaldi@unifi.it
} 
important stakeholders to be involved in the environmental strategy. A greater compliance and a risk reduction can be reached when the Financial institutions, Environmental NGOs, Rivals and Shareholders are involved in the environmental strategy. In this regards, results highlighted the importance of Environmental auditing programme for suppliers and Sustainable disclosures. Moreover, in fashion sector, the companies that pursued "Lower cost" as competitive advantage aim at obtaining from environmental strategy a great access to capital and lower cost of capital.

Keywords Environmental sustainability - Textile, clothing and leather (TCL)

\section{Introduction}

The Textile, Leather and Clothing (TCL) sector represents one of the most important economies in the European Industry and it contributes to a large extent to the global fashion system: consistent investments, emphasis on upmarket products and global leadership have all made Europe the world's biggest exporter of treated leather, as well as the second biggest exporter of textiles and clothing, with respectively $24 \%$ and $26 \%$ of world sales (Euratex 2014). In 2014 the textile and clothing industry realised a turnover of $€ 165.3$ Billion and employed 1.6 Million people in more than 170,000 companies (Euratex 2015). The leather industry represented in 2011 a turnover of $€ 31$ Billion and consisted of about 24.000 SMEs and employs 392.264 people (ESSC TCLF 2014). Within this context, Italy is the principal actor of this economy with 18.7 billion Euros of value added and more than a third of the total EU production (Eurostat 2013a, b, c).

At the same time the TCL industry is recognised as one of the most polluting sector in the world, being a huge consumer of water, electricity and chemicals, and discharging massive quantities of wastes to land (Bevilacqua et al. 2014). Therefore, the TCL industry is one of the sector that has received the highest public attention, and one of the most challenged by the sustainability concerns that have recently emerged in the media, including Detox by Greenpeace, Sustainable Apparel Coalition, Clean Clothes Campaign, Røadmap to Zero Discharge Of Hazardous Chemicals (ZDHC), Fashion Revolution, only to mention a few.

In this context sustainability initiatives are crucial for fashion firms to increase customers' and stakeholders' engagement and loyalty and stay competitive in the market (Smith 2003). However, there is still a dichotomy between today's reality and the industry's opportunities to leverage sustainability, as well as between the rhetoric and the reality in pursuing a sustainability approach (Rhee and Lee 2003): while many companies commit to sustainability, few put their commitment into actions (Chi 2011). In literature some preliminary results have been presented on how and to what extent TLC companies implement sustainability practices along their supply chain (De Brito et al. 2008; Chi 2011; Caniato et al. 2012; Resta et al. 
2014), but a comprehensive analysis encompassing the all the corporate environmental management areas is still missing.

Thus, the aim of this paper is to contribute to enrich this research field, analysing how the implementation of environmental strategies and practices boost corporate competitiveness in the Textile, Clothing and Leather (TCL) sector.

The paper is structured as follow. Section 2 presents an overview of the theoretical background, while in Sect. 3 the research methodology is explained. Section 4 reports the results of this work. Finally, in Sects. 5 and 6 discussion of results, conclusions and the future work are described.

\section{Theoretical Background}

Over the past decades, the issue of environmental sustainability has steadily gained greater prominence on the corporate agenda of TCL companies, resulting in an increasing research interest in analysing the implementation of a corporate environmental management framework. In particular, corporate environmental management encompasses all the strategic and operational efforts to minimize the negative environmental impact of firm's business operations (Cramer 1998). In line with "traditional" corporate management, environmental management become manifest through an integrated approach encompassing (Carmona-Moreno et al. 2004): (i) "environmental strategy", that denotes a firm's competitive orientation towards the environmental pillar of sustainability; (ii) "environmental management practices" that refer to all the strategic, tactical and operational activities which aim to protect the environment; and (iii) "environmental competitiveness and profitability" that denotes the contribution of a company's sustainability management to its overall competitiveness.

Environmental strategy. A key point in the discussion of environmental strategies is the fit between environmental strategy and corporate competitive strategy (Baumgartner and Ebner 2010), as well as their integration (Galbreath 2009; Murthy 2012): any sustainability approach that is "fragmented" and "disconnected from business and strategy" will "obscure many of the greatest opportunities for companies to benefit society" (Kramer and Porter 2006) and to increase company's alignment with the expectation of its stakeholders (Henriques and Sadorsky 1999).

Moreover, different types of environmental strategy could be implemented by a company, based on their proactivity level that typically ranges between two extreme positions: environmental reactivity, representative of companies that only implement the minimal compulsory changes to meet regulations, and environmental proactivity, typical of companies that voluntarily take measures to reduce their impact on the natural environment. Several works conceptualised this path from reactivity to proactivity by establishing a number of progressive stages, assuming a single and linear path that companies follow when developing their commitment to the natural environment (Jabbour 2010). 
Environmental Management Practices (EMPs) refer to all the measures and activities aimed at executing an environmental strategy, thereby reducing the environmental impact caused by a company's business (Sroufe et al. 2002). The practices mostly applied in the TCL industry can be classified into five categories (Resta et al. 2014): product, supply chain management, process, governance and culture.

The first category includes all the practices related to the design of sustainable products, as well as the required raw materials. Practices which can be included in this dimension are the systematic adoption of environmental assessment tools (e.g. LCA, Carbon Footprint, Water Footprint) related to the final product, the utilisation of methodologies to improve the product design and development process (e.g. Eco Design), as well as products certifications (i.e., Oeko-Tex, Seri.Co, Ecolabel, GOTS, etc.) and in general practices for the improvement of product environmental sustainability. Consequently, the "Product" variable includes also actions related to the use of raw materials recycled from waste, produced from renewable sources, close to the sourcing point (e.g. zero km raw materials suppliers), and/or certified. Practices related to the reuse of packaging are also considered.

The second category deals with practices related to the establishment, management and control of a green supply chain, whereby the key dimensions of corporate sustainability are combined with supply chain characteristics. Evaluation of environmental performance of suppliers, verified by environmental auditing programme, has received the highest attention in supplier selection for sustainable supply chain management. Another important practice in this area refers to the implementation of collaborative relationships with suppliers in order to improve the environmental sustainability levels of purchased materials and technologies. With reference to transportation, the use of hybrid or electric transport systems is also included.

The third dimension is related to production processes. In this area, practices related to energy, water, process materials and waste are included. Moreover, process and environmental management system certification (e.g. ISO 14000, EMAS) are considered as relevant.

The fourth dimension refers to initiatives aiming at managing green activities and the relationship with all the stakeholders. Sustainability reports, Sustainability Advisory Board, dedicated corporate function or business unit, website dedicated to green activities are practices considered in this dimension.

Finally, the culture dimension deals the with introduction of training programs involving both internal than external stakeholders, with the goal of spreading a green culture.

Environmental competitiveness and profitability. Savitz and Weber (2006) suggest that "a sustainable company is one that creates profit for its shareholders while protecting the environment and improving the lives of those with whom it interacts". Indeed if environmental issues are successfully incorporated into corporate strategies and practices, sustainability can be transformed into competitive advantage, making a business case for environmental sustainability (Epstein and Roy 2003; Salzmann et al. 2005). 
Empirical research has very much focused on the relationship between environmental strategy and business performance, offering contradictory results. As reviewed by Blomgren (2011), while some studies demonstrated that firm's environmental strategies lead to improved business performance, others found either insignificant or negative relationships. Moreover, considering the fashion sector, while there is growing evidence of the use of environmental management practices by TCL companies (Caniato et al. 2012; Choi et al. 2014; Cooperrider and Fry 2012; Na and Na 2015; Resta et al. 2014), there is still a selective evidence on the benefits that might be obtained. Lo et al. (2012) focuses on the adoption of a specific practice only (adoption of ISO 14000 certification) and its impact on firms' financial performance, confirming a significant positive impact on ROA and ROS. Therefore, the argument of whether or not environmental strategies lead to improved business performance is far from resolved and further empirical research is thus needed to understand the link between environmental management practices and business competitiveness.

\section{Research Methodology}

In order to analyse how the implementation of environmental strategies and practices boost corporate competitiveness in the Textile, Clothing and Leather (TCL) sector, an explanatory survey research has been conducted (Malhotra and Grover 1998). In theory building research, no matter how inductive the approach, a prior view of the general constructs or categories and their relationships is valuable in order to: (i) shape the initial research design, (ii) measure constructs more accurately, and (iii) have a firmer empirical grounding for the emergent theory (Forza 2002). Therefore, a set of variables of interest have been identified for each corporate environmental management dimension, as described in the Theoretical Background.

The primary data for this study was collected through a web survey in June-July 2014. The online survey was chosen among different ways to administer the questionnaire to avoid costs, reduce bias and automate data. The research was initiated with the design of the research model and the related questionnaire, which was the main source for data collection. A pilot-test questionnaire with a set of selected companies was administered to prove viability and to detect difficulties in the interpretation of questions. The inputs received from the pre-test were analysed and weighted in the final version of the questionnaire. It comprised 27 questions and was intended to elicit information on environmental strategy, management practices and competitiveness. In particular, the questionnaire was categorised into 4 sections:

- Section A-Company's general information

- Section B-Environmental strategy

- Section C-Environmental management practices (EMPs) 


\section{- Section D-Environmental competitiveness}

The questionnaire was administered to a subset of companies operating in the TCL Italian sector included in the AIDA data base (NACE code: 13, 14, 15). From the total population of companies having 13, 14 and 15 NACE code, the present study investigates the firms that have explicitly declared on their website the adoption of almost one sustainability practice, totaling 514. Each company was contacted by email, addressed to potential respondent managers knowledgeable about the phenomenon to be measured, and reporting the link to the web-questionnaire. Follow-up telephone calls after 2 weeks resulted in 343 total usable responses returned to the authors, corresponding to a response rate of $67 \%$.

The collected data were then analysed through the association rule analysis, as described in the following paragraph.

\subsection{Association Rule Analysis}

Agrawal et al. (1993) introduced association rules for discovering regularities between products in large-scale transaction data recorded by point-of-sale systems in supermarkets. Following the original definition of Agrawal et al. (1993) the problem of association rule mining is defined as: let $\mathrm{I}=\left\{i_{1}, i_{2}, \ldots, i_{n}\right\}$ be a set of $\mathrm{n}$ binary attributes called items, and let $\mathrm{D}=\left\{t_{1}, t_{2}, \ldots, t_{m}\right\}$ be a set of transactions called the database. Each transaction in D has a unique transaction ID and contains a subset of the items in I. A rule is defined as an implication of the form $\mathrm{A} \rightarrow \mathrm{B}$, where $\mathrm{A}$ and $\mathrm{B}$ are known as item sets, and $\mathrm{A}, \mathrm{B} \subseteq \mathrm{I}, \mathrm{A} \cap \mathrm{B}=\varnothing$. Agrawal et al. (1993) considered each rule composed by two different sets of items, called item-set (A and B). Hence, A is named the antecedent or left-hand-side (LHS) and B is the consequent or right-hand-side (RHS). Moreover in order to select rules of interest, three common metrics (support (1), confidence (2) and lift (3)) are defined for measuring association between the antecedent and the consequent.

$$
\begin{gathered}
\text { Support }=\frac{\#\{L H S \cup R H S\}}{\#\{\text { all records }\}} \\
\text { Confidence }=\frac{\text { Support }\{L H S \cup R H S\}}{\text { Support }\{L H S\}} \\
\text { Lift }=\frac{\text { Support }\{\text { LHS } \cup R H S\}}{\text { Support }\{L H S\} \times \text { Support }\{R H S\}}
\end{gathered}
$$

Therefore, the "Support" indicates how frequent combination of item-sets occurs in the dataset for an alternative. In contrast, the confidence is equivalent to the conditional probability, the probability of finding the RHS of the rule in transactions 
under the condition that these transactions also contain the LHS. Furthermore, the lift tells us whether the antecedent and the consequent are independent (zero), positively correlated (above unity), or negatively correlated (below unity).

\section{Results}

\subsection{Sample Characteristics}

The sample is mostly composed by companies belonging to the textile sector (88\%). The remaining part is equally divided into clothing $(6 \%)$ and leather $(6 \%)$ companies. Moreover, $7 \%$ of the sample companies have turnover higher than 50 million $€$ (large companies), $24 \%$ are medium-size companies (50 mil.€ < Turnnover $<10$ mil.€) and $69 \%$ are small and micro-size companies (Turnover $<10$ mil.€).

\subsection{Association Analysis}

Association Rule Mining is performed on the data set (343 cases) and 58 items in the data set using the Apriori algorithm implementation from the arules package for $\mathrm{R}$. In order to determine relevant mined rules, only rules with a support greater than 0.9 have been considered. Indeed, as the support measure evaluates the probability that items occur, probability greater than $90 \%$ has been taken into account.

We imposed the different levels of firms' competitive strategies (Product differentiation, Cost Leadership and Hybrid), firms' competitive advantage due to sustainability practices (Revenue growth, Cost Saving and Compliance and risk) and "strategic behaviour", as right-hand-side (RHS) item-set, in order to investigate which factors mainly influence these aspects. All other variables have been inserted as left-hand-side (LHS) variables.

The RHS and LHS variables considered are mainly dummy variable, as they take value 0 or 1 to indicate the absence or presence of the effect. In addition, a five point Likert scale represents the variable "Integration of environmental and competitive strategy" and measures the proactivity level of a company.

Tables 1 and 2 report the results of the analysis ordered in decreasing order by confidence. These rules have satisfied the minimum support (0.9) and minimum confidence (0.9) along with lift value greater than one. The support and confidence columns indicate that there is both a frequent combination of item-sets and a high conditional probability of finding the RHS of the rule in transactions under the condition that these transactions also contain the LHS. Moreover a Lift greater than 1 confirms that the variables are positively correlated. Significant values have been found only with the Compliance and risk (Table 1) and Cost leadership variables (COMPADV_COST) (Table 2). 
Table 1 Association rules output (Consequent "Compliance and risk")

\begin{tabular}{|c|c|c|c|c|c|c|}
\hline $\begin{array}{l}\text { Rule } \\
\text { no. }\end{array}$ & LHS & $=>$ & RHS & Support & Confidence & Lift \\
\hline 1 & $\begin{array}{l}\left\{\text { STAKE_INT_PRIM }_{3}=1,\right. \\
\left.\text { STAKE_SECO }_{2}=1\right\}\end{array}$ & $=>$ & $\begin{array}{l}\{\text { Compliance } \\
\text { and risk }=1\}\end{array}$ & 0.908 & 0.989 & 1.6 \\
\hline 2 & $\left\{\right.$ STAKE_SECO $\left.{ }_{2}=1\right\}$ & $=>$ & $\begin{array}{l}\{\text { Compliance } \\
\text { and risk }=1\}\end{array}$ & 0.960 & 0.986 & 1.3 \\
\hline 3 & $\left\{\right.$ STAKE_INT_PRIM $\left._{3}=1\right\}$ & $=>$ & $\begin{array}{l}\{\text { Compliance } \\
\text { and risk }=1\}\end{array}$ & 0.931 & 0.986 & 1.3 \\
\hline 4 & $\begin{array}{l}\left\{\text { STAKE_SECO }_{2}=1,\right. \\
\left.\text { PRACT_TRANS }_{2}=1\right\}\end{array}$ & $=>$ & $\begin{array}{l}\{\text { Compliance } \\
\text { and risk }=1\}\end{array}$ & 0.921 & 0.986 & 1.2 \\
\hline 5 & $\begin{array}{l}\{\text { STAKE_SECO } \\
2=1, \\
\text { PRACT_RAWM } \\
3=1\}\end{array}$ & $=>$ & $\begin{array}{l}\{\text { Compliance } \\
\text { and risk }=1\}\end{array}$ & 0.921 & 0.986 & 1.2 \\
\hline 6 & $\begin{array}{l}\left\{\text { STAKE_INT_PRIM }_{2}=1,\right. \\
\left.\text { STAKE_SECO }_{2}=1\right\}\end{array}$ & $=>$ & $\begin{array}{l}\{\text { Compliance } \\
\text { and risk }=1\}\end{array}$ & 0.911 & 0.986 & 1.2 \\
\hline 7 & $\left\{\right.$ STAKE_SECO $\left.{ }_{1}=1\right\}$ & $=>$ & $\begin{array}{l}\{\text { Compliance } \\
\text { and risk }=1\}\end{array}$ & 0.999 & 0.986 & 1.2 \\
\hline 8 & $\left\{\right.$ PRACT_SUPPLY $\left.{ }_{2}=1\right\}$ & $=>$ & $\begin{array}{l}\{\text { Compliance } \\
\text { and risk }=1\}\end{array}$ & 0.908 & 0.986 & 1.2 \\
\hline 9 & $\left\{\right.$ PRACT_GOV $\left.{ }_{1}=1\right\}$ & $=>$ & $\begin{array}{l}\{\text { Compliance } \\
\text { and risk }=1\}\end{array}$ & 0.901 & 0.986 & 1.2 \\
\hline
\end{tabular}

\section{Discussion and Implications}

Many rules defined in the results section can be used by managers in order to develop the best strategy for integrating environmental and competitive strategy. To sum up and explain the results obtained with "Compliance and risk" as a consequent (Table 1), it is possible to state that:

- Rules 1, 2, 3 and 6 of Table 1 mean that compliance and risk advantage is most likely to be reached when the Financial institutions, Environmental NGOs and Shareholders are involved in the environmental strategy. The study highlights a strong connection between finance and the environment. The environmental risks that confront a financial institution's clients such as violation of laws and responsibility for cleaning up contamination have an impact on their bottom line and, in turn, can pose risks to the institution and shareholders.

- Rules 4 and 5 mean that compliance and risk advantage is most likely to be reached when Environmental NGOs are involved in the environmental strategy, while "Zero km" raw material and Low impact vehicles are the environmental practices carried out. Most Environmental NGOs recognise the benefits of the wide variety of internal environmentally beneficial actions that contribute to energy savings and sustainable production. These may include the use of low impact vehicles and "Zero km" raw materials. 


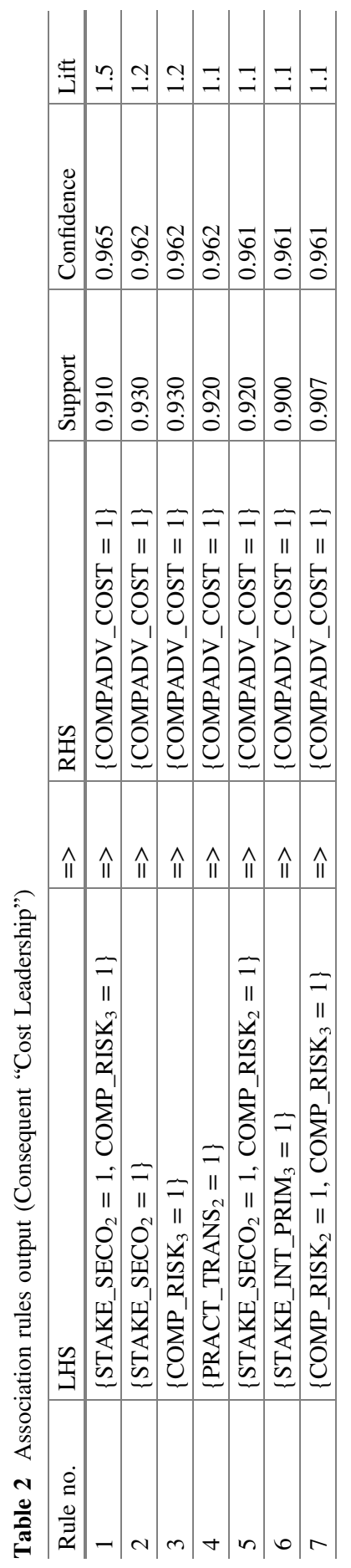


- Rule 7 means that compliance and risk is most likely to be reached when Rivals are an important stakeholder. One-to-one interviews with company managers about this point highlighted that many companies aim at gaining competitiveness, in comparison to their rivals, from various environmental policies and regulation.

- Rule 8 and 9 mean that compliance and risk advantage is most likely to be reached when Environmental auditing programme for suppliers is carried out and Sustainable disclosures are developed.

Analysing the results obtained with "Cost Leadership" as a consequent (Table 2) it is possible to state that:

- In fashion sector, companies that pursued "Lower cost" as competitive advantage aim at obtaining from environmental strategy a great access to capital (rules 1, 3 and 7) and lower cost of capital (rules 5 and 7).

- Moreover, these companies involved in their environmental strategy Environmental NGOs and Financial institutions (rules 1, 2, 5 and 6).

- Many fashion companies are becoming aware of the possible risks that NGOs could present to their business. Moreover, environmental NGOs are recognising the pivotal role of finance in today's economy and are seeking ways to influence where capital flows.

\section{Conclusion}

In this work an investigation of environmental strategies carried out by in fashion sector has been carried out analyzing a sample of 343 companies.

Several rules have been generated in order to identify relationships among sustainable practices, impacts of environmental strategy and stakeholders typology involved in the strategy.

In the case examined in this work, the intrinsic structure and complexity of the data collected might jeopardize the use of traditional tools for analysis since the variables present the following critical characteristics:

- high dimensionality: a high number of variables is a problem of considerable importance for standard statistical analysis in general;

- interaction and dependency: the relations between the independent variables can be a problem particularly in parametric analyses, which typically adopt the independence hypothesis;

- non-homogeneity and non-linearity: different relationships may exist between the variables in several parts of the measurement space.

As a data mining technique, Association Rules methodology demonstrated to be a powerful alternative to the frequently used traditional parametric techniques. 
From this point of view Association Rules can be considered a complementary tool to parametric methods, guiding the researcher towards a more thorough understanding of the data.

\section{References}

Agrawal R, Tomasz I, Arun S (1993) Mining association rules between sets of items in large databases. In: Proceedings of the 1993 ACM SIGMOD international conference on management of data. SIGMOD '93. ACM, NY, pp 207-216. doi:10.1145/170035.170072

Baumgartner R, Ebner D (2010) Corporate sustainability strategies: sustainability profiles and maturity levels. Sustain Dev 18(2):76-89

Bevilacqua M, Ciarapica FE, Mazzuto G, Paciarotti C (2014) Environmental analysis of a cotton yarn supply chain. J Clean Prod 82(1):154-165

Blomgren A (2011) Does corporate social responsibility influence profit margins? A case study of executive perceptions. Corp Soc Responsib Environ Manage 18(5):263-274

Caniato F, Caridi M, Crippa L, Moretto A (2012) Environmental sustainability in fashion supply chains: an exploratory case based research. Int J Prod Econ 135(2):659-670

Carmona-Moreno E, Céspedes-Lorente J, De Burgos-Jiménez J (2004) Environmental strategies in Spanish hotels: contextual factors and performance. Serv Ind J 24(3):101-130

Chi T (2011) Building a sustainable supply chain: An analysis of corporate social responsibility (CSR) practices in the Chinese textile and apparel industry. J Text Inst 102:837-848

Choi TM, Chiu C-H, Govindan K, Yue X (2014) Sustainable fashion supply chain management: the European scenario. Eur Manage J 32(5):821-822

Cooperrider D, Fry R (2012) Tied into a single garment of destiny. J Corp Citizsh 45:3-4

Cramer J (1998) Environmental management: from "fit" to "stretch". Bus Strategy Environ 7(3):162-172

De Brito M, Carbone V, Blanquart C (2008) Towards a sustainable fashion retail supply chain in Europe: organisation and performance. Int J Prod Econ 114(2):534-553

Epstein MJ, Roy M (2003) Making the business case for sustainability. J Corp Citizsh 9:79-96

ESSC TCLF (European Sector Skills Council-Textile Clothing Leather Footwear) (2014). Report 2014. http://europeanskillscouncil.t-c-l.eu/en/reports.aspx

Euratex (2014) Annual report. Taking action for the future of the European textile and clothing industry. Euratex, Brussels

Euratex (2015) The EU-28 Textile and clothing industry in the year 2014. http://euratex.eu/library/ statistics/key-data/key-data-details/?tx_ttnews\%5Btt_news\%5D=4846\&cHash=a43f98d261ba88233db94846a8f7e08e

Eurostat (2013a) Manufacture of textiles statistics-NACE Rev 2-Statistics explained. http:// epp.eurostat.ec.europa.eu/statistics_explained/index.php/Manufacture_of_textiles_statistics_-NACE_Rev._2

Eurostat (2013b) Manufacture of wearing apparel statistics-NACE Rev 2-Statistics explained. http://epp.eurostat.ec.europa.eu/statistics_explained/index.php/Manufacture_of_wearing_apparel_ statistics_-_NACE_Rev._2

Eurostat (2013c) Manufacture of leather and related products statistics-NACE Rev 2-Statistics explained. http://epp.eurostat.ec.europa.eu/statistics_explained/index.php/Manufacture_of_ leather_and_related_products_statistics_-_NACE_Rev._2

Forza C (2002) Survey research in operations management: a process-based perspective. Int J Oper Prod Manage 22(2):152-194

Galbreath J (2009) Building corporate social responsibility into strategy. Eur Bus Rev 21(2):109-127 
Henriques I, Sadorsky P (1999) The relationship between environmental commitment and managerial perceptions of stakeholder importance. Acad Manage J 42(1):87-99

Jabbour C (2010) Non-linear pathways of corporate environmental management: a survey of ISO 14001-certified companies in Brazil. J Clean Prod 18(12):1222-1225

Kramer M, Porter ME (2006) Strategy and society: the link between competitive advantage and corporate social responsibility. Harvard Bus Rev 84(12):76-92

Lo CKY, Yeung ACL, Cheng TCE (2012) The impact of environmental management systems on financial performance in fashion and textiles industries. Int J Prod Econ 135(2):561-567

Malhotra MK, Grover V (1998) An assessment of survey research in POM: from constructs to theory. J Oper Manage 16(4):407-425

Murthy V (2012) Integrating corporate sustainability and strategy for business performance. World J Entrep Manage Sustain Dev 8(1):5-17

$\mathrm{Na}$ Y, Na DK (2015) Investigating the sustainability of the Korean textile and fashion industry. Int J Clothing Sci Technol 27(1):23-33

Resta B, Stefano D, Pinto R, Bandinelli R, Rinaldi R, Ciarapica FE (2014) Practices for environmental sustainability in the textile, clothing and leather sectors: the italian case. Int $\mathrm{J}$ Oper Quant Manage 20(3):101-133

Rhee SK, Lee SY (2003) Dynamic change of corporate environmental strategy: rhetoric and reality. Bus Strategy Environ 12(3):175-190

Salzmann O, Ionescu-Somers A, Steger U (2005) The business case for corporate sustainability: literature review and research options. Eur Manage J 23(1):27-36

Savitz AW, Weber K (2006) The triple bottom line. Jossey-Bass, San Francisco

Smith NC (2003) Corporate social responsibility: whether or how? Calif Manage Rev 45(4):52-76

Sroufe R, Montabon F, Narasimhan R, Wang X (2002) Environmental management practices. Greener Manage Int 40:23-44 